\title{
Ganodermanontriol, a lanostanoid triterpene from Ganoderma lucidum, suppresses growth of colon cancer cells through $\boldsymbol{B}$-catenin signaling
}

\author{
ANDREJ JEDINAK ${ }^{1}$, ANITA THYAGARAJAN-SAHU ${ }^{1}$, JIAHUA JIANG ${ }^{1}$ and DANIEL SLIVA I,2,3 $^{1,2}$ \\ ${ }^{1}$ Cancer Research Laboratory, Methodist Research Institute, 1800 N. Capitol Ave, E504, Indianapolis, \\ IN 46202; ${ }^{2}$ Department of Medicine, and ${ }^{3}$ Indiana University Simon Cancer Center, \\ Indiana University School of Medicine, Indianapolis, IN 00000, USA
}

Received September 24, 2010; Accepted November 15, 2010

DOI: $10.3892 /$ ijo.2011.898

\begin{abstract}
Colorectal cancer is one of the most common cancers in men and women in the world. Previous molecular studies have revealed that deregulation of the $\beta$-catenin signaling pathway plays a crucial role in the progression of colorectal cancer. Therefore, modulation of the B-catenin pathway offers a strategy to control colorectal cancer progression. The medicinal mushroom Ganoderma lucidum (GL) is a rich source of triterpenes with anticancer properties. Here, we show that ganodermanontriol (GNDT), a purified triterpene from GL, inhibited proliferation of HCT-116 and HT-29 colon cancer cells without a significant effect on cell viability. Moreover, GNDT inhibited transcriptional activity of B-catenin and protein expression of its target gene cyclin D1 in a dose-dependent manner. A marked inhibition effect was also seen on Cdk-4 and PCNA expression, whereas expression of Cdk-2, p21 and cyclin E was not affected by the GNDT treatment. In addition, GNDT caused a dosedependent increase in protein expression of E-cadherin and B-catenin in HT-29 cells. Finally, GNDT suppressed tumor growth in a xenograft model of human colon adenocarcinoma cells HT-29 implanted in nude mice without any sideeffects and inhibited expression of cyclin D1 in tumors. In conclusion, our data suggest that ganodermanontriol might be a potential chemotherapeutic agent for the treatment of cancer.
\end{abstract}

\section{Introduction}

Colorectal cancer (CRC) is the fourth most common noncutaneous malignancy and the second most frequent cause of

Correspondence to: Dr D. Sliva, Cancer Research Laboratory, Methodist Research Institute, 1800 N Capitol Ave, E504, Indianapolis, IN 46202, USA

E-mail: dsliva@clarian.org

Key words: Ganoderma lucidum, ganodermanontriol, colon cancer, ß-catenin, cyclin D1 cancer deaths in the United States (1). In 2010, an estimated 142,570 cases of colorectal cancer will be diagnosed, and 51,370 people will die from the disease (2). Molecular studies have revealed that over $90 \%$ of CRC arises from mutation in Wnt signaling pathway (3). ß-catenin is a multifunction protein and plays a key role in Wnt signaling pathway. In addition, $\beta$-catenin has two independent functions in the cell: one in the linking the cytoplasmic side of cadherinmediated cell-cell contacts to the actin cytoskeleton, another in signaling that involves transactivation in complex with transcription factors of the lymphoid enhancing factor/T-cell factor (LEF-1/Tcf) family. Elevated $\beta$-catenin levels in colorectal cancer caused by mutations in $\beta$-catenin or by the adenomatous polyposis coli molecule (APC), which regulates B-catenin degradation, result in the binding of $B$-catenin to LEF/Tcf and increased transcriptional activation of target genes including cyclin D1, c-myc and proliferator-activated receptor $\delta$, which play important role in colorectal cancer (4-7). Cyclin D1 is a critical oncogene involved in the regulation of progression through the G1 phase of the cell cycle, thereby contributing to cell proliferation (8). In addition, the expression of cyclin D1 is elevated in $\sim 30 \%$ of human adenocarcinomas of the colon (9) and represents a good molecular target for cancer therapy or chemoprevention (10).

At the present time there is an increasing public interest in the secondary metabolites from higher fungi for discovering new drugs or lead compounds (11). The significance of bioactive molecules from higher fungi is that it might offer an alternative approach to synthetic drugs, which very often have side-effects and poor bioavailability. Ganoderma lucidum (Leyss. ex Fr.) Karst is a medicinal mushroom that has been utilized for centuries in East Asia to prevent or treat various diseases and to reduce the likelihood of cancer invasion and metastasis (12). The anticancer properties of G. lucidum have been attributed to a variety of bioactive compounds, including lanostane-based triterpenes (13-15). One of the biologically active molecules isolated from Ganoderma species is ganodermanontriol (GNDT) which showed cytotoxicity against cancer cells (13), and antioxidant, anti-HIV-1 protease, and anti-complement activities, respectively (16-18).

In the present study, we examined the effect of GNDT on colon cancer cells in vitro and in vivo. Here, we show that 
GNDT suppressed proliferation of human colon cancer cells and inhibited growth of tumors in a xenograft model of colon cancer. In summary, our data demonstrate a molecular mechanism responsible for the anti-cancer activity of GNDT and suggest the therapeutic use of GNDT for the treatment of colon cancer.

\section{Materials and methods}

Materials. Ganodermanontriol (GNDT) was purchased from ChromaDex (Santa Ana, CA, USA) and Planta Analytica (Danbury, CT, USA). Dimethylsulfoxide (DMSO), cremophor and alcohol were purchased from Sigma (St. Louis, MO, USA).

Cells. Human colon cancer cell lines HT-29 and HCT-116 were purchased from ATCC (Manassas, VA, USA). The cells were cultured in Dulbecco's modified Eagle's medium (DMEM) supplemented with $10 \%$ fetal bovine serum (FBS), penicillin $(50 \mathrm{U} / \mathrm{ml})$ and streptomycin $(50 \mathrm{U} / \mathrm{ml})$. The media and antibiotics were purchased from Invitrogen (Carlsbad, CA, USA). The cells were grown at $37^{\circ} \mathrm{C}$ in $5 \% \mathrm{CO}_{2}$ and $95 \%$ humidity.

Proliferation. HT-29 and HCT-116 cells $\left(2.5 \times 10^{5}\right)$ were plated in 96-well plates. The cells were let to attach overnight, followed by the treatment with GNDT $(0-80 \mu \mathrm{M})$ or vehicle (DMSO) at indicated times. The antiproliferative effect of GNDT was determined by tetrazolium salt method according to the manufacturer's instructions (Promega, Madison, WI, USA) as described before (19).

Viability. Cell viability of HT-29 and HCT-116 was determined after incubation with GNDT $(0-80 \mu \mathrm{M})$ for $24 \mathrm{~h}$ by staining with trypan blue as described (20).

Western blot analysis. HT-29 cells $\left(1 \times 10^{6}\right)$ were treated with GNDT $(0-80 \mu \mathrm{M})$ for $24 \mathrm{~h}$ and the whole cell extracts were prepared as described previously (21). Equal amounts of proteins $(15 \mu \mathrm{g} /$ lane $)$ were separated on NuPAGE $4-12 \%$ Bis-Tris gels (Invitrogen) and transferred to a PVDF membrane (Millipore, Bedford, MA, USA). The protein expression was determined by corresponding primary antibodies: Cdk-2, Cdk-4, cyclin D1, cyclin E, PCNA and p21 (Santa Cruz Biotechnology, Santa Cruz, CA, USA), B-catenin (Upstate Cell Signaling Solutions, Lake Placid, NY, USA), E-cadherin (BD Biosciences, San Jose, CA, USA) diluted to 1:1000 in blocking solution. The membranes were striped and reprobed with $\beta$-actin antibody (Santa Cruz Biotechnology).

DNA transfection and reporter gene assay. HT-29 and HCT116 cells $\left(5 \times 10^{5}\right)$ were seeded into 6-well plates in DMEM medium containing $10 \%$ fetal bovine serum (FBS), penicillin $(50 \mathrm{U} / \mathrm{ml})$ and streptomycin $(50 \mathrm{U} / \mathrm{ml})$ prior to transfection. The cells were transfected with the TOP-FLASH or FOPFLASH luciferase reporter constructs $(0.5 \mu \mathrm{g})$, gift from R.T. Moon, and B-galactosidase expression vector pCH110 $(0.5 \mu \mathrm{g})$. Transient transfections were performed with the Lipofectamine 2000 and Plus reagent (Invitrogen) in DMEM medium without FBS according to the manufacturer's instructions.
Twenty-four hours after transfection, cells were washed with DPBS and the medium was replaced with DMEM with $2 \%$ FBS, followed by treatment with GNDT $(0-80 \mu \mathrm{M})$ or vehicle for $24 \mathrm{~h}$. Cells were harvested and cell extracts prepared as previously described (21). Luciferase activity was determined using the Lmax (Molecular Devices, Sunnyvale, CA, USA) and normalized for equal numbers $\beta$-galactosidase units.

Human colon cancer xenograft experiments. Male nude immunodeficient mice (nu/nu), 6 weeks old, were purchased from Harlan (Indianapolis, IN, USA) and housed in accordance with protocol approved by the Institutional Laboratory Animal Care and Use Committee of the Methodist Research Institute. On day 0 , human colon cancer HT-29 cells $\left(5 \times 10^{6}\right)$ suspended in $0.2 \mathrm{ml}$ of DMEM medium were inoculated subcutaneously (s.c.) in the right flank of each mouse. Seven days after inoculation, mice were randomly divided into two groups: control $(n=11)$ and treatment group $(n=10)$ treated daily with intraperitoneal (i.p.) injection of $100 \mu 1$ of a vehicle [10\% DMSO, 70\% cremophor/ethanol (3:1), and 20\% PBS] or GNDT (3 mg/kg of body weight) dissolved in DMSO and adjusted to the final concentration of $10 \%$ DMSO, $70 \%$ mixture of ethanol and cremophor (3:1) and 20\% PBS daily for 28 days. Tumor sizes were measured three times a week using calipers and their volumes were calculated using a standard formula: tumor volume $\left(\mathrm{mm}^{3}\right)=(\mathrm{W} \times \mathrm{L}) 2 \times 1 / 2$, where $\mathrm{L}$ is the length and $\mathrm{W}$ is the width of the tumor. The animals were sacrificed after 28 days and dissected tumors were fixed in $10 \%$ neutral formalin. Body weight was measured twice weekly.

Immunohistochemistry. Formalin-fixed paraffin-embedded blocks were sectioned at $5 \mu \mathrm{m}$ and placed on positive-charged slides. The expression of cyclin-D1 was evaluated after incubation with rabbit anti-cyclin D1 primary antibody (Santa Cruz Biotechnology) and quantified by counting cyclin D1 positive cells in 3 different fields from 3 animals of the control and GNDT group.

Statistical and densitometric analysis. Data represent the mean $\pm \mathrm{SD}$ of three independent experiments. The significance was evaluated by ANOVA or Student's t-test. Tumor volume measurements were summarized by treatment group using descriptive statistics (mean $\pm \mathrm{SD}$ ). The comparison of the change in tumor volume and immunohistochemical staining for cyclin D1 between groups was performed using a two-sample Student t-test. The value of $\mathrm{p}<0.05$ was considered significant. Quantification of Western blot data was performed by measuring optical densities of autoradiograms with HP-Scanjet 550c and analyzed by UN-SCAN-IT software (Silk Scientific, Orem, UT, USA). The ratios of specific proteins to $\beta$-actin were calculated by standardizing the ratios of each control to the unit value.

\section{Results}

Effect of GNDT on colon cancer cell growth and viability. We have recently demonstrated that an extract containing lanostane-type triterpenes from Ganoderma lucidum suppressed growth of human colon cancer cells in vitro and in animals 
<smiles>CC(CCC(O)C(C)(O)CO)[C@H]1CC[C@]2(C)C3=CCC4C(C)(C)C(=O)CC[C@]4(C)C3=CC[C@]12C</smiles>

Figure 1. Structure of ganodermanontriol (GNDT).

(15). Therefore, we investigated whether GNDT (Fig. 1), a purified lanostanoid triterpene from G. lucidum, has the potency to suppress proliferation of colon cancer cells. As seen in Fig. 2A and B, GNDT significantly suppressed growth of HCT-116 and HT-29 colon cancer cell lines in a time- and dose-dependent manner, respectively. Moreover, the growth-inhibitory effect of GNDT was stronger in HT-29 than in HCT-116 cells. To determine whether this antiprolife- rative effect was cytotoxic or cytostatic we performed a viability assay (Fig. 2C and D) and we found that GNDT did not affect viability of HCT-116 or in HT-29 cells. Therefore, the data suggest that the effect of GNDT on colon cancer was mainly cytostatic.

Effect of GNDT on cell cycle regulatory proteins. In our previous study (15) we have seen that triterpene extract from G. lucidum caused cell cycle arrest at G0/G1 in HT-29 cells. Therefore, we performed a pilot cell cycle analysis of HT-29 cells treated with GNDT $(50 \mu \mathrm{M})$ by flow cytometry and we have also found cell cycle arrest at G0/G1 phase (not shown). In the next step we wanted to determine which proteins involved in G0/G1 phase are affected by the GNDT treatment. HT-29 cell were treated with GNDT $(0-80 \mu \mathrm{M})$ and Western blot analysis were performed in whole cell lysates. We observed that GNDT markedly suppressed the expression of cyclin D1, which was down-regulated in a dose-dependent manner (Fig. 3). Moreover, GNDT also down-regulated expression of cyclin-dependent kinase Cdk-4 and proliferating cell nuclear antigen (PCNA), whereas expression of Cdk-2, p21 and cyclin E in HT-29 cells was not affected by the GNDT
A

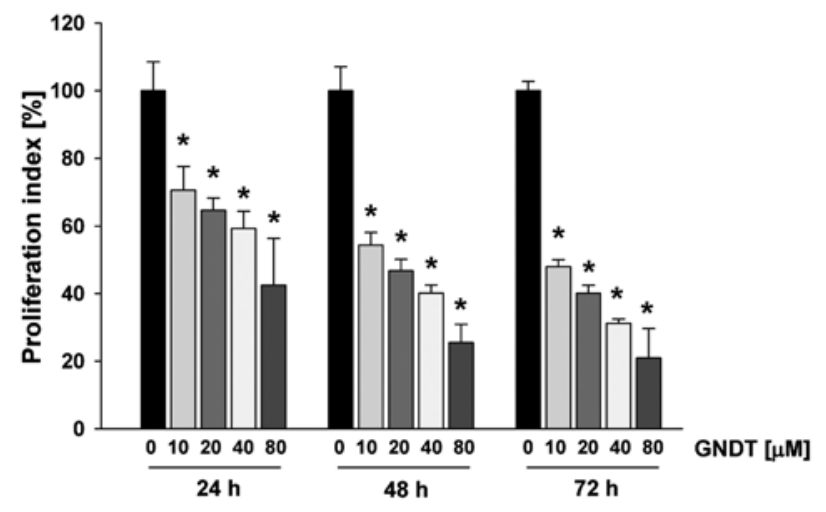

C

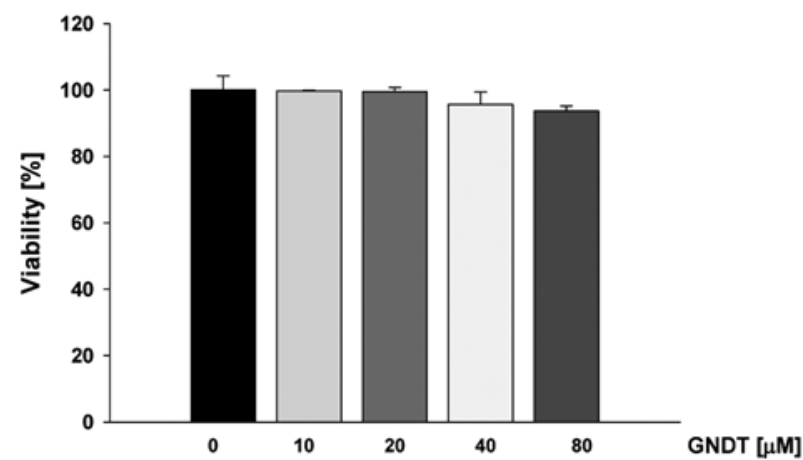

B

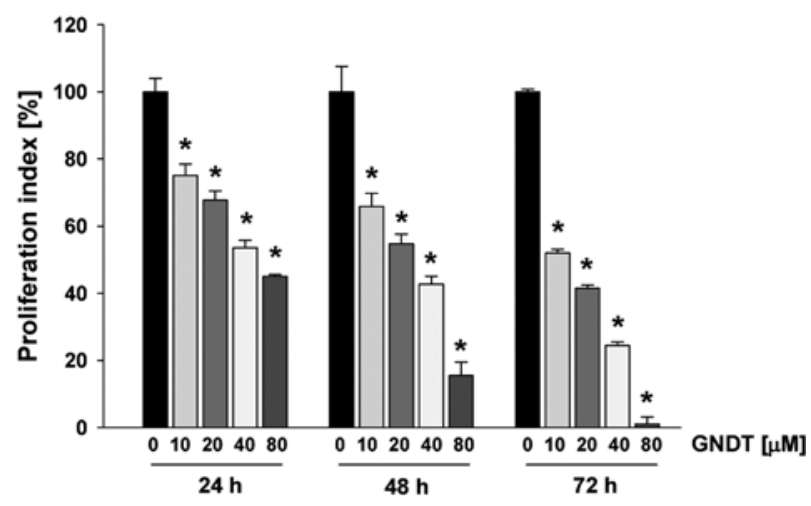

D

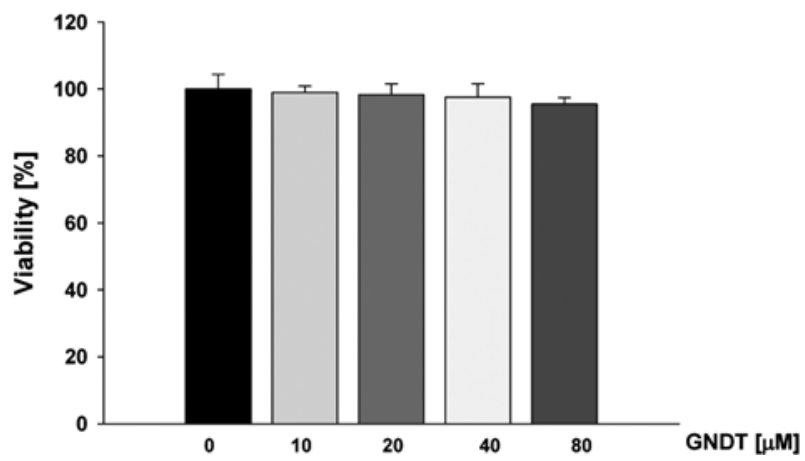

Figure 2. Effect of GNDT on proliferation and viability of HCT-116 and HT-29 cells. (A) HCT-116 and (B) HT-29 cells were treated with ganodermanontriol $(0-80 \mu \mathrm{M})$ for $24-72 \mathrm{~h}$ and cell proliferation was assessed as described in Materials and methods. (C) HCT-116 and (D) HT-29 cells were treated with GNDT $(0-80 \mu \mathrm{M})$ for $24 \mathrm{~h}$ and cell viability was determined as described in Materials and methods. The data are means \pm S.D. of triplicate measurements. *Statistically different from control group, $\mathrm{p}<0.05$, analyzed by ANOVA. 

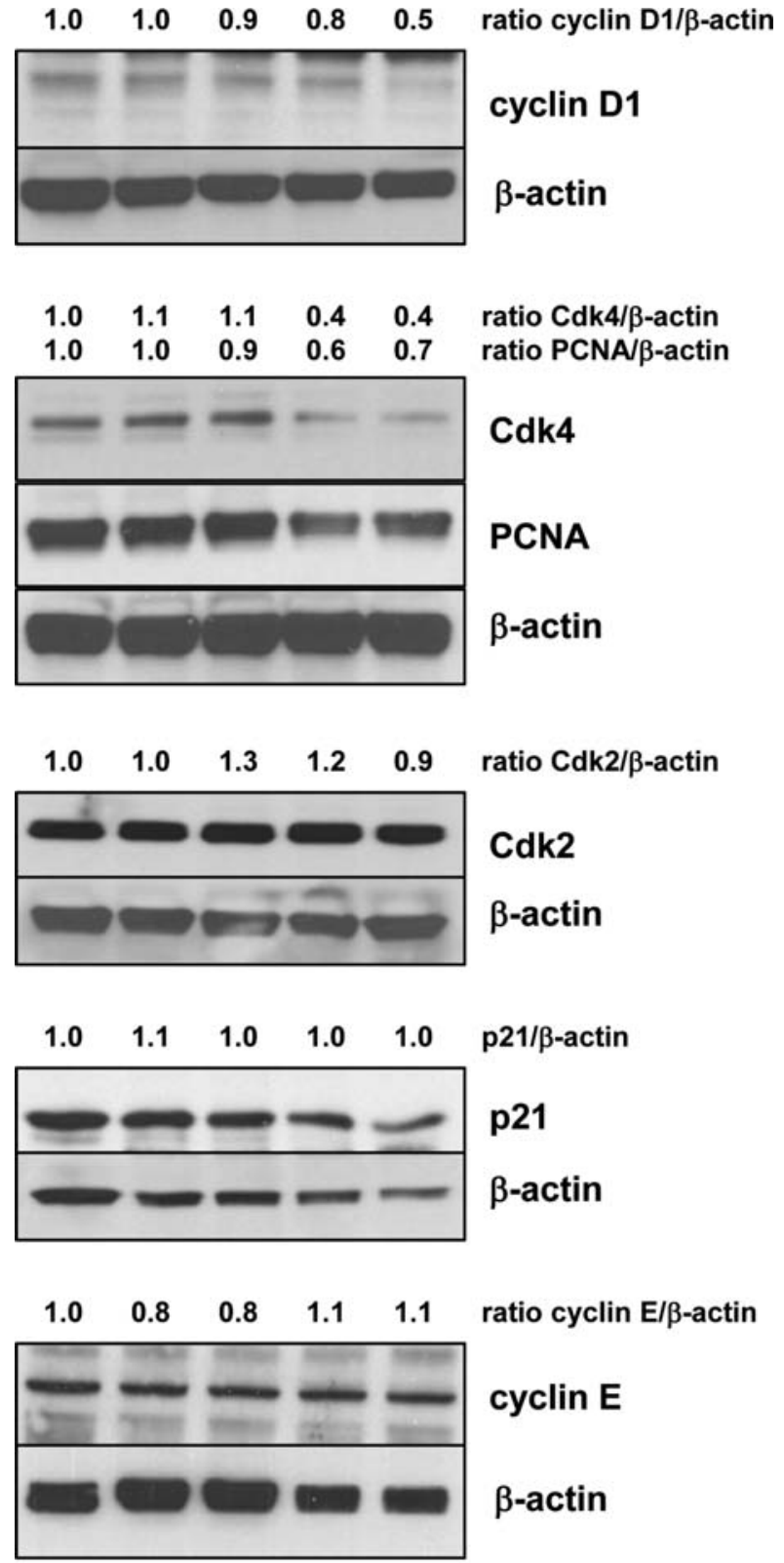

\section{$\begin{array}{llllll}0 & 10 & 20 & 40 & 80 & \text { GNDT }[\mu M]\end{array}$}

Figure 3. Effect of GNDT on expression of cell cycle regulatory proteins in HT-29 cells. HT-29 cells were treated with GNDT $(0-80 \mu \mathrm{M})$ for $24 \mathrm{~h}$. The expression of cyclin D1, Cdk-4, PCNA, Cdk-2, p21 and cyclin E was evaluated in whole cell extracts as described in Materials and methods. The equivalent amount of protein loading was verified by reprobing the blot with anti-ß-actin antibody. The expression levels were quantified by densitometry as described in Materials and methods. The results are representative of three separate experiments.

treatment (Fig. 3). Thus, these results suggest that cytostatic effect of GNDT could be specific to the down-regulation of cyclin D1 expression.

Effect of GNDT on $\beta$-catenin transcription activity and $\beta$-catenin expression. Cyclin D1 is one of the main target genes regulated by $ß$-catenin pathway in colorectal cancer. Therefore, we investigated whether GNDT regulates transcription activity of B-catenin in colon cancer cells. HCT-116 and HT-29 cells were transfected with reporter gene constructs containing wild-type LEF/Tcf (TOP-Flash) or mutated LEF/Tcf (FOP-Flash) B-catenin binding sites and treated with GNDT as described in Materials and methods. As seen in Fig. 4A and B, GNDT significantly decreased specific B-catenin/LEF/Tcf activity in a dose-dependent manner in HCT-116 and HT-29 cells, respectively. On the other hand, there was no effect on $B$-catenin/LEF/Tcf activity in cells transfected with reporter gene containing mutated LEF/Tcf binding sites, except the $80-\mu \mathrm{M}$ dose of GNDT in HCT-116transfected cells (Fig. 4A). Thus, our data confirm that GNDT suppresses transcription activity of $\beta$-catenin resulting in the down-regulation of expression of cyclin D1 in colon cancer cells.

As mentioned above, B-catenin possesses binary function in cell signaling. $\beta$-catenin associates with the cytoplasmic tail of E-cadherin in the cell membrane (22), and is therefore involved in the E-cadherin-mediated cell junction. In order to evaluate the effect of GNDT on the expression of B-catenin and E-cadherin in colon cancer cells, we treated HT-29 cells with GNDT and performed Western blot analysis as described in Materials and methods. As seen in Fig. 4C, GNDT markedly induced expression of $\beta$-catenin and E-cadherin in a doseresponse manner in HT-29 cells.

Effect of GNDT in vivo. Our in vitro data suggest that GNDT regulates cell cycle of human colon adenocarcinoma cells HT-29 through down-regulation of cell cycle regulatory proteins, mainly cyclin D1. Therefore, in the next step, we evaluated the effect of GNDT in vivo by using xenograft model of human colon adenocarcinoma cells HT-29 subcutaneosly implanted into nude mice. Intraperitoneal administration of GNDT (3.0 mg ganodermanontriol/ $\mathrm{kg}$ of body weight/day) for 28 days significantly suppressed tumor volume in nude mice (Fig. 5A). As seen in Fig. 5A and B, GNDT suppressed tumor volume and tumor weight; however, tumor weight reduction was not significant (Fig. 5B). Moreover, we did not observe any side-effect of GNDT and there were no differences in body weight between control and treatment groups (Fig. 5C), suggesting that GNDT is not toxic. The immunohistochemistry revealed that expression of cyclin D1 in tumors was significantly reduced in mice treated with GNDT (Fig. 6).

\section{Discussion}

Multiple molecular mechanisms seem to be involved in the tumor suppressive effects of triterpenes from G. lucidum. Therefore, we examined the cellular and molecular effects of ganodermanontriol (GNDT), a biologically active triterpene isolated from G. lucidum on the growth of human colon cancer cells. In this study, we demonstrate, for the first time, that GNDT inhibits proliferation of colon cancer cells by down-regulating expression of cyclin D1 via modulation of ß-catenin pathway.

Colorectal cancer remains one of the most common cancers in the Western world and amongst the top three causes of cancer morbidity and death (23). Although chemotherapy and radiation therapy have been attempted in adjuvant and palliative treatments, a more effective adjuvant therapy is needed for colon cancer patients. Nearly half of all patients 
A

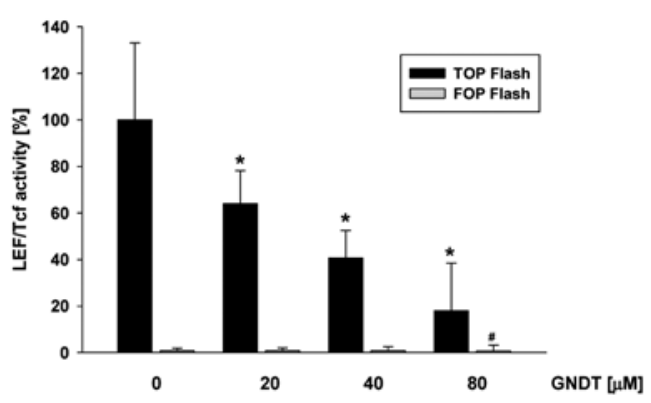

C

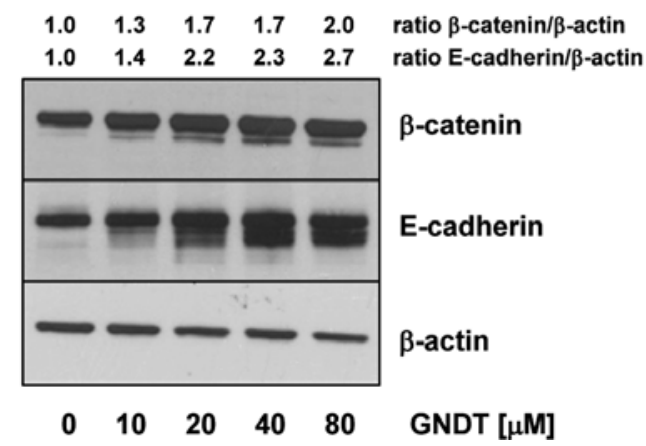

A

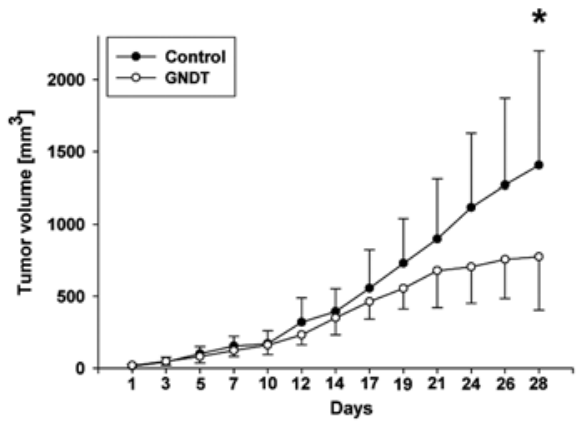

C

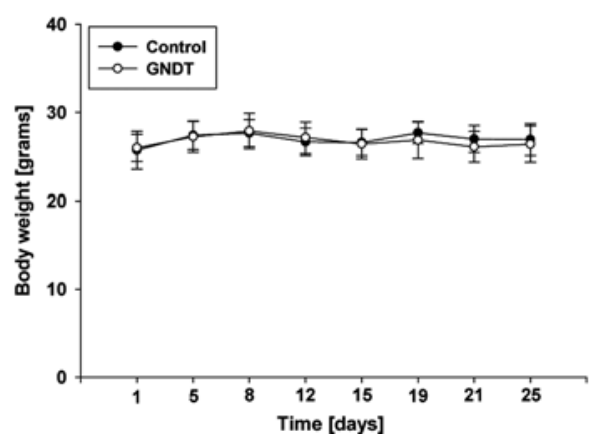

B

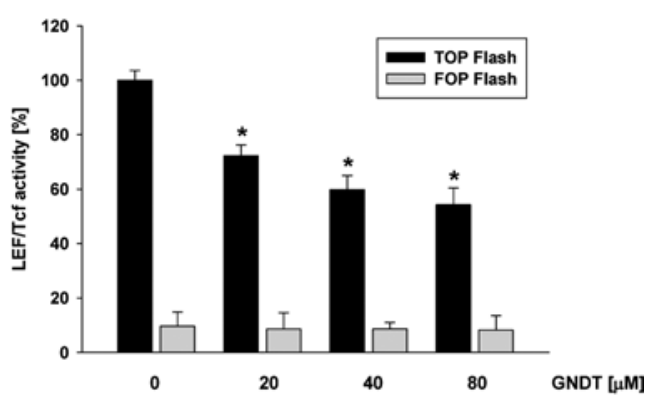

Figure 4. Effect of GNDT on B-catenin activity and B-catenin expression in colon cancer cells. (A) HCT-116 and (B) HT-29 cells were transfected with $0.5 \mu \mathrm{g}$ TOP- or FOP-Flash reporter gene construct and $0.5 \mu \mathrm{g}$ of $\beta$-galactosidase expression vector $\mathrm{pCH} 110$. Twenty-four hours after transfection, the cells were treated with GNDT $(0-80 \mu \mathrm{M})$ for $24 \mathrm{~h}$ and B-catenin activity was determined as described in Materials and methods. Each bar represents the mean \pm SD of three experiments; ${ }^{*}$ Different from control TOP-Flash $\mathrm{p}<0.05$. "Different from control FOP-Flash $\mathrm{p}<0.05$, analyzed by ANOVA. (C) The expression of $\beta$-catenin and E-cadherin in whole cell extracts from HT-29 cells treated with GNDT $(0-80 \mu \mathrm{M})$ for $24 \mathrm{~h}$ were analyzed by Western blot analysis with the respective antibodies. The equivalent amount of protein was verified by reprobing the blot with anti- $\beta$-actin antibody. The expression level of $\beta$-catenin and E-cadherin vs. B-actin were quantified by densitometry as described in Materials and methods. The results are representative of three separate experiments.

B

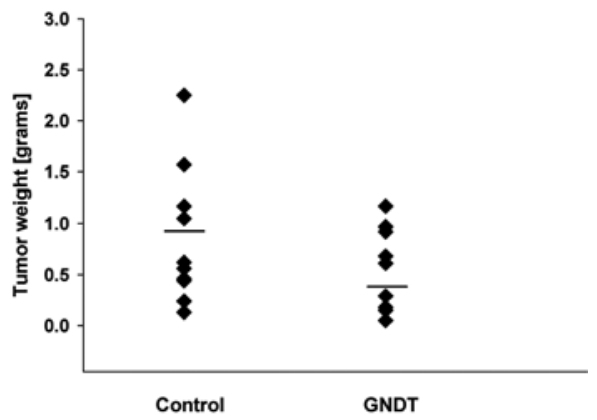

Figure 5. GNDT inhibits growth of colon cancer cells in vivo. (A) Tumor volume. HT-29 cells were inoculated s.c. in the right flank of each mouse. Seven days after inoculation, mice were randomly divided into two groups and treated with GNDT (i.p., $3 \mathrm{mg} / \mathrm{kg}$ of body weight/day, $\mathrm{n}=10$ ) or vehicle $(n=11)$ for 28 days. Tumor volume was measured three times a week. Data are mean $\pm \mathrm{SD},{ }^{*}$ Significantly different from control $(\mathrm{p}<0.05)$ using a twosample Student t-test. (B) Tumor weight. (C) Body weight of mice.

anticancer and antimetastatic activity $(25,26)$. The medicinal mushroom $G$. lucidum is a rich source of triterpenes with anticancer activity. Moreover, triterpenes from G. lucidum have been reported to also possess hepatoprotective, anti- with colon cancer still die of metastatic disease after curative surgery (24). Therefore, new therapeutic drugs with reduced side-effects and better bioavailability are needed. Triterpenoids are structurally diverse organic compounds with promising 
A

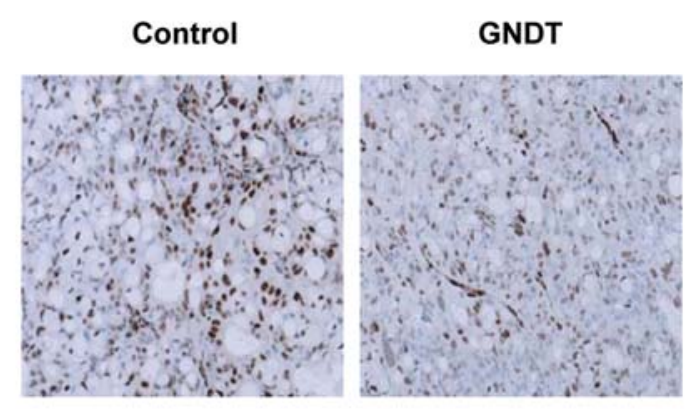

B

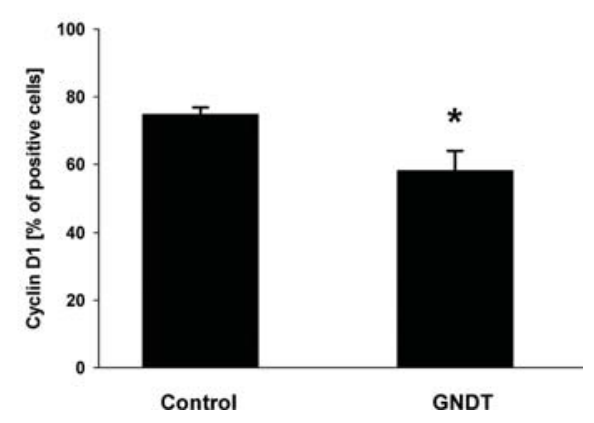

Figure 6. Effect of GNDT on cyclin D1 expression in tumors. (A) Tumors dissected from animals were weighed, sectioned and stained for cyclin D1 as described in Materials and methods. (B) The expression of cyclin D1 was quantified as described in Materials and methods. Data are the mean \pm SD ( $=3$ ). *Significantly different from control $(\mathrm{p}<0.05)$ using a two-sample Student t-test.

hypertensive, hypocholesterolemic, anti-histaminic effects and anti-angiogenic activity (27). Furthermore, some of these triterpenes affected platelet aggregation, inhibited complement inhibition (28) and demonstrated good bioavailability $(29,30)$.

In the present study, we demonstrate that GNDT inhibits proliferation of colon cancer cells and tumor growth by the down-regulation of expression of cyclin D1 and Cdk-4. We have previously demonstrated that other triterpenes, ganoderic acid $\mathrm{A}$ and $\mathrm{H}$, suppressed growth of breast cancer cells through the inhibition of expression of Cdk-4 (31). Moreover, ganoderic acid DM suppressed proliferation of prostate cancer cells and inhibited $5 \alpha$-reductase activity (32), whereas ganoderic acid $\mathrm{T}$ suppressed proliferation and tumor growth in mice by the up-regulation of expression of tumor suppressor p53 and by the induction of apoptosis (33), and ganoderic acid X suppressed proliferation of hepatocellular carcinoma cells through the inhibition of topoisomerase I and II (34). In addition, lucidenic acid $\mathrm{A}, \mathrm{C}$ and $\mathrm{N}$ induced cell cycle arrest at G1 phase, whereas lucidenic acid B induced apoptosis of leukemia cells (35).

As mentioned above, the most prominent effect of GNDT was seen on expression of cyclin D1, a target gene of the B-catenin/LEF-1/Tcf pathway (4). The function of $\beta$-catenin is dual: i) as a structural component of the cell adhesion/actin cytoskeleton network and ii) as a signaling molecule when localized in the nucleus $(36,37)$. After the release of $\beta$-catenin from its intracellular binding partner, B-catenin translocates to the nucleus, binds to the LEF/Tcf binding site in the promoter regions of target genes and participates in the transcriptional regulation of specific genes associated with differentiation, proliferation and malignant transformation (38-41). Here, we show that GNDT inhibits transcription activity of B-catenin, finally resulting in the down-regulation of expression of cyclin D1 and inhibition of proliferation of colon cancer cells. On the other hand, GNDT increases total protein levels of B-catenin in HT-29 cells. Thus, inhibition of B-catenin transcription activity and induction of protein levels B-catenin might suggest shift in the relocalization of B-catenin to the cell membrane where it might bind to the cytoplasmic tail of E-cadherin (22). The adhesion protein E-cadherin is a well-recognized tumor and invasion suppressor that plays a crucial suppressive role in the transition from adenoma to carcinoma in several epithelial cancers, including colorectal cancers (42). Indeed, here we show that GNDT also induces protein levels of E-cadherin in a dose-dependent manner in HT-29 cells. Therefore, our data are in concert with previous reports, demonstrating the suppression of ß-catenin signaling and associated increase in E-cadherin levels with other natural chemopreventive compounds: vitamin D, indole-3-carbinol and tangeretin (43-45). In agreement with our in vitro studies, GNDT also suppresses tumor growth in a xenograft model of colon cancer, and this inhibition is associated with the downregulation of expression of cyclin D1 in tumors. Therefore, our study suggests that GNDT possesses antiproliferative activity through the modulation of $\beta$-catenin signaling and its target gene cyclin D1 in vitro and in vivo.

In summary, our data indicate that ganodermanontriol, a purified triterpene from G. lucidum, could be a suitable candidate for the therapy of colon cancer. Further preclinical and clinical studies are warranted.

\section{Acknowledgments}

The authors thank Collin Terry for the help with the statistical analysis of in vivo experiment and Randall T. Moon for TOP- and FOP-Flash reporter gene constructs. This study was supported by the Methodist Research Institute, Clarian Health, Inc.

\section{References}

1. Wolpin BM and Mayer RJ: Systemic treatment of colorectal cancer. Gastroenterology 134: 1296-1310, 2008.

2. Jemal A, Siegel R, Xu J and Ward E: Cancer Statistics, 2010 CA Cancer J Clin 60: 277-300, 2010.

3. Giles RH, van Es JH and Clevers H: Caught up in a Wnt storm: Wnt signaling in cancer. Biochim Biophys Acta 1653: 1-24, 2003.

4. Shtutman M, Zhurinsky J, Simcha I, Albanese C, D'Amico M, Pestell R and Ben-Ze'ev A: The cyclin D1 gene is a target of the beta-catenin/LEF-1 pathway. Proc Natl Acad Sci USA 96: $5522-5527,1999$

5. He TC, Sparks AB, Rago C, Hermeking H, Zawel L, da Costa LT, Morin PJ, Vogelstein B and Kinzler KW: Identification of c-MYC as a target of the APC pathway. Science 281: 1509-1512, 1998.

6. He TC, Chan TA, Vogelstein B and Kinzler KW: PPARdelta is an APC-regulated target of nonsteroidal anti-inflammatory drugs. Cell 99: 335-345, 1999. 
7. Tetsu $\mathrm{O}$ and McCormick F: Beta-catenin regulates expression of cyclin D1 in colon carcinoma cells. Nature 398: 422-426, 1999.

8. Yan YX, Nakagawa H, Lee MH and Rustgi AK: Transforming growth factor-alpha enhances cyclin D1 transcription through the binding of early growth response protein to a cis-regulatory element in the cyclin D1 promoter. J Biol Chem 272: 33181-33190, 1997.

9. Arber N, Hibshoosh H, Moss SF, Sutter T, Zhang Y, Begg M, Wang S, Weinstein IB and Holt PR: The PRAD-1/cyclin D1 oncogene product accumulates aberrantly in a subset of colorectal carcinomas. Int J Cancer 58: 568-573, 1994.

10. Freemantle SJ, Liu X, Feng Q, Galimberti F, Blumen S, Sekula D, Kitareewan S, Dragnev KH and Dmitrovsky E: Cyclin degradation for cancer therapy and chemoprevention. J Cell Biochem 102: 869-877, 2007.

11. Zhong JJ and Xiao JH: Secondary metabolites from higher fungi: discovery, bioactivity, and bioproduction. Adv Biochem Eng Biotechnol 113: 79-150, 2009.

12. Weng CJ and Yen GC: The in vitro and in vivo experimental evidences disclose the chemopreventive effects of Ganoderma lucidum on cancer invasion and metastasis. Clin Exp Metastasis 27: 361-369, 2010

13. Gao JJ, Min BS, Ahn EM, Nakamura N, Lee HK and Hattori M: New triterpene aldehydes, lucialdehydes A-C, from Ganoderma lucidum and their cytotoxicity against murine and human tumor cells. Chem Pharm Bull (Tokyo) 50: 837-840, 2002.

14. Lin SB, Li CH, Lee SS and Kan LS: Triterpene-enriched extracts from Ganoderma lucidum inhibit growth of hepatoma cells via suppressing protein kinase $\mathrm{C}$, activating mitogenactivated protein kinases and G2-phase cell cycle arrest. Life Sci 72: 2381-2390, 2003.

15. Thyagarajan A, Jedinak A, Nguyen H, Terry C, Baldridge LA, Jiang J and Sliva D: Triterpenes from Ganoderma lucidum induce autophagy in colon cancer through the inhibition of p38 mitogen-activated kinase (p38 MAPK). Nutr Cancer 62: 630-640, 2010 .

16. Zhu M, Chang Q, Wong LK, Chong FS and Li RC: Triterpene antioxidants from Ganoderma lucidum. Phytother Res 13: 529-531, 1999.

17. Min BS, Nakamura N, Miyashiro H, Bae KW and Hattori M: Triterpenes from the spores of Ganoderma lucidum and their inhibitory activity against HIV-1 protease. Chem Pharm Bull (Tokyo) 46: 1607-1612, 1998

18. Min BS, Gao JJ, Hattori M, Lee HK and Kim YH: Anticomplement activity of terpenoids from the spores of Ganoderma lucidum. Planta Med 67: 811-814, 2001.

19. Jedinak A and Sliva D: Pleurotus ostreatus inhibits proliferation of human breast and colon cancer cells through p53-dependent as well as p53-independent pathway. Int J Oncol 33: 1307-1313, 2008

20. Sliva D, Labarrere C, Slivova V, Sedlak M, Lloyd FP Jr and Ho NW: Ganoderma lucidum suppresses motility of highly invasive breast and prostate cancer cells. Biochem Biophys Res Commun 298: 603-612, 2002

21. Sliva D, Rizzo MT and English D: Phosphatidylinositol 3-kinase and NF-кB regulate motility of invasive MDA-MB-231 human breast cancer cells by the secretion of urokinase-type plasminogen activator (uPA). J Biol Chem 277: 3150-3157, 2002.

22. Orsulic S, Huber O, Aberle H, Arnold S and Kemler R: E-cadherin binding prevents beta-catenin nuclear localization and beta-catenin/LEF-1-mediated transactivation. J Cell Sci 112: $1237-1245,1999$

23. Sengupta N, Gill KA, MacFie TS, Lai CS, Suraweera N, Mcdonald S and Silver A: Management of colorectal cancer: a role for genetics in prevention and treatment? Pathol Res Pract 204: 469-477, 2008

24. Wang JJ, Lee JY, Chen YC, Chern YT and Chi CW: The antitumor effect of a novel differentiation inducer, 2, 2-Bis (4-(4-amino-3-hydroxyphenoxy) phenyl) adamantane (DPA), in combinatory therapy on human colon cancer. Int J Oncol 28 : 1003-1012, 2006

25. Petronelli A, Pannitteri G and Testa U: Triterpenoids as new promising anticancer drugs. Anticancer Drugs 20: 880-892, 2009.
26. Jedinak A, Muckova M, Kostalova D, Maliar T and Masterova I: Antiprotease and antimetastatic activity of ursolic acid isolated from Salvia officinalis. Z Naturforsch C 61: 777-782, 2006.

27. Sliva D: Medicinal potential of Ganoderma lucidum. In: Applied Mycology. Rai M and Bridge PD (eds). CAB International, Oxon, Cambridge, pp173-196, 2009.

28. Boh B, Berovic M, Zhang J and Lin ZB: Ganoderma lucidum and its pharmaceutically active compounds. Biotechnol Annu Rev 13: 265-301, 2007.

29. Adamec J, Jannasch A, Dudhgaonkar S, Jedinak A, Sedlak M and Sliva D: Development of a new method for improved identification and relative quantification of unknown metabolites in complex samples: determination of a triterpenoid metabolic fingerprint for the in situ characterization of Ganoderma bioactive compounds. J Sep Sci 32: 4052-4058, 2009.

30. Zhang Q, Zuo F, Nakamura N, Ma CM and Hattori M: Metabolism and pharmacokinetics in rats of ganoderiol $\mathrm{F}$, a highly cytotoxic and antitumor triterpene from Ganoderma lucidum. J Nat Med 63: 304-310, 2009

31. Jiang J, Grieb B, Thyagarajan A and Sliva D: Ganoderic acids suppress growth and invasive behavior of breast cancer cells by modulating AP-1 and NF-kappaB signaling. Int J Mol Med 21: 577-584, 2008

32. Liu J, Shiono J, Shimizu K, Kukita A, Kukita T and Kondo R: Ganoderic acid DM: anti-androgenic osteoclastogenesis inhibitor. Bioorg Med Chem Lett 19: 2154-2157, 2009.

33. Tang W, Liu JW, Zhao WM, Wei DZ and Zhong JJ: Ganoderic acid T from Ganoderma lucidum mycelia induces mitochondria mediated apoptosis in lung cancer cells. Life Sci 80: 205-211, 2006.

34. Li CH, Chen PY, Chang UM, Kan LS, Fang WH, Tsai KS and Lin SB: Ganoderic acid X, a lanostanoid triterpene, inhibits topoisomerases and induces apoptosis of cancer cells. Life Sci 77: 252-265, 2005

35. Hsu CL, Yu YS and Yen GC: Lucidenic acid B induces apoptosis in human leukemia cells via a mitochondria-mediated pathway. J Agric Food Chem 56: 3973-3980, 2008.

36. Nelson WJ and Nusse R: Convergence of Wnt, beta-catenin, and cadherin pathways. Science 303: 1483-1487, 2004.

37. Harris TJ and Peifer M: Decisions, decisions: beta-catenin chooses between adhesion and transcription. Trends Cell Biol 15: 234-237, 2005.

38. Adams CL and Nelson WJ: Cytomechanics of cadherinmediated cell-cell adhesion. Curr Opin Cell Biol 10: 572-577, 1998.

39. Huber O, Bierkamp $C$ and Kemler R: Cadherins and catenins in development. Curr Opin Cell Biol 8: 685-691, 1996.

40. Huber O, Korn R, McLaughlin J, Ohsugi M, Herrmann BG and Kemler R: Nuclear localization of beta-catenin by interaction with transcription factor LEF-1. Mech Dev 59: 3-10, 1996.

41. Yamada S, Pokutta S, Drees F, Weis WI and Nelson WJ: Deconstructing the cadherin-catenin-actin complex. Cell 123: 889-901, 2005.

42. Perl AK, Wilgenbus P, Dahl U, Semb H and Christofori G: A causal role for E-cadherin in the transition from adenoma to carcinoma. Nature 392: 190-193, 1998

43. Pálmer HG, González-Sancho JM, Espada J, Berciano MT, Puig I, Baulida J, Quintanilla M, Cano A, de Herreros AG, Lafarga M and Muñoz A: Vitamin $\mathrm{D}(3)$ promotes the differentiation of colon carcinoma cells by the induction of E-cadherin and the inhibition of beta-catenin signaling. J Cell Biol 154: 369-387, 2001.

44. Meng Q, Qi M, Chen DZ, Yuan R, Goldberg ID, Rosen EM, Auborn K and Fan S: Suppression of breast cancer invasion and migration by indole-3-carbinol: associated with up-regulation of BRCA1 and E-cadherin/catenin complexes. J Mol Med 78: 155-165, 2000.

45. Brack ME, Boterberg T, Depypere HT, Stove C, Leclercq G and Mareel MM: The citrus methoxyflavone tangeretin affects human cell-cell interactions. Adv Exp Med Biol 505: 135-139, 2002. 